\title{
ДЕМОГРАФИЧЕСКИЙ ПЕРЕХОД: СПОР О ТЕОРИЯХ РАЗНОГО УРОВНЯ
}

\author{
НАТАЛИЯ ЗВЕРЕВА
}

\begin{abstract}
Предмет статьи - проблемы формирования теории демографического перехода (демографической револючии), обусловленные попьтками отождествления в демографической теории общего и специифического в воспроизводстве населения стран мира, его количественных и качественных изменений, необходимостью формирования содержательной (объясняющей) общей демографической теории на основе междисииплинарного подхода. Цель работь: на основе анализа двух основных в нашей стране точек зрения на теорию демографического перехода показать их внутренние противоречия. Использование общефилософской методологии (анализа, синтеза, комплексного и междисииплинарного подхода, соотношения общего и специифического, историкодемографических обобщений) дает возможность выявить связи этой теории с нерешенными ещче проблемами междисциплинарного подхода к изучению воспроизводства населения. Обосновано, что ученые спорят о теориях разного уровня, а разработка содержательной общей теории демографического перехода непосредственно зависит от выбора стратегий ее формирования, важнейшей из которых выступает демографо-экономико-историко-социологический подход.
\end{abstract}

Ключевые слова: воспроизводство населения, смертность, рождаемость, демографическая теория, демографический переход, демографическая революичя, демографическая система, тип мотиваџии демографического поведения.

\section{ВВЕДЕНИЕ}

Воспроизводство населения на протяжении человеческой истории всегда было связано с социально-экономическим развитием - этого никто не отрицает. Демографические исследования также обусловливались социально-экономическими потребностями (нужды страхования; необходимость объяснения причин социальной нестабильности; определение величины затрат на социальную сферу, социальную политику; учет демографического фактора в международных экономических и политических отношениях).

Однако в отличие от экономики с ее развитым теоретическим направлением исследований теоретическая демография выглядит бедной Золушкой. Отдельные ученые стараются превратить ее в принцессу (сказочную или реальную) или «рассыпать ее, как сказочную тыкву» на мелкие кусочки, превращая ее во множество «теоретических демографий» отдельных стран. Цель работы: на основе анализа двух основных в нашей стране точек зрения А.Г. Вишневского и М.А. Клупта на теорию воспроизводства населения показать внутренние противоречия формирующейся теории демографического перехода как общей теории воспроизводства населения.

НАТАЛИЯ ВИКТОРОВНА ЗВЕРЕВА, МОСКОВСКИЙ ГОСУДАРСТВЕННЫЙ УНИВЕРСИТЕТ ИМЕНИ М.В. ЛОМОНОСОВА. Россия.

E-mail: zvereva52@yandex.ru

СТАТЬЯ ПОСТУПИЛА В РЕДАКЦИЮ В НОЯБРЕ 2014 Г. 
В начале статьи ставится проблема необходимости дальнейшей содержательной разработки (т.е. объясняющей переход от одного этапа к другому) теории демографического перехода как общей теории. По моему мнению, именно наличие такой теории и является стержнем теоретической демографии как единой науки ${ }^{1}$ (или целостного направления исследований в демографии; в научной школе МГУ говорят о наличии системы демографических наук, одной из которых выступает теоретическая демография). Далее дается анализ аргументации сторонников и противников существования общей теории воспроизводства населения. Особое внимание уделяется точке зрения А.Г. Вишневского, благодаря работам которого эта теория начала обсуждаться и в нашей стране. Об общей теории населения или о теории демографического перехода писали А. Сови, Р. Лестаж, Дж. Колдуэлл, ван де Каа, Д. Коугилл, Д. Скоффилд, Д.И. Валентей, А.Я. Кваша, А. Авдеев и много других ученых ${ }^{2}$. На основании проведенного анализа делается вывод, что развитие общей теории демографического перехода и ее содержание зависят от понимания, что же такое «общее», и от стратегий ее формирования на основе междисциплинарного подхода. В настоящее время общая теория воспроизводства населения пока представляет собой схему отдельных этапов изменений показателей смертности и рождаемости, их соотношения (включают в них и миграцию). Содержательная, объясняющая взаимосвязанные изменения демографических процессов общая теория населения ${ }^{3}$ эклектична (если она рассматривается как теория «одинаковости» основных показателей воспроизводства населения в каждой стране и их факторов), что и является одной из причин отказа от нее и перехода к региональным эмпирическим содержательным (объясняющим воспроизводство населения не только через сопоставление смертности и рождаемости, но и через включение в это объяснение социального контекста) теориям воспроизводства населения. Основная перспективная стратегия формирования общей теории воспроизводства населения состоит в его междисциплинарных демографоэкономико-историко-социологических исследованиях типичной страны (критерий классические этапы перехода). Пока, полагаю, существует только более или менее «общая» схема этапов перехода, в которой отсутствуют содержание - социально-экономические факторы (хотя бы снижения смертности, включая детскую и младенческую, если следовать концепции А.Г. Вишневского) $)^{4}$.

\footnotetext{
${ }^{1}$ Хотя вопросы о возможности существования науки без теории ставятся [Szoltysek 2007].

2 Общая теория населения А. Сови рассматривается мною как набор отдельных фактов, характеризующих воспроизводство населения и его отдельные процессы. Общая теория народонаселения в научной школе МГУ едина (изучает «развитие населения», главной частью которого выступает и воспроизводство населения). Науки в системе знаний о народонаселении и «сопредельные» науки связаны с воспроизводством населения как причина или следствие. Общая теория воспроизводства демографической системы А.Г. Вишневского делает акцент на ее «самовоспроизведение» - это «чистая теория только воспроизводства населения»

3 Здесь и далее речь идет о теории воспроизводства населения.

4 А.Г. Вишневский считает необходимым интегрировать концепцию эпидемиологического перехода в концепцию демографического перехода, их этапы, видимо, ощущая неполноту существующей концепции (об этом он писал в первом номере «Демографического обозрения» [Вишневский 2014а]), но пока это не очень получается.
} 


\section{ТЕОРИЯ ДЕМОГРАФИЧЕСКОГО ПЕРЕХОДА КАК ОБЩАЯ ТЕОРИЯ ВОСПРОИЗВОДСТВА НАСЕЛЕНИЯ}

В многоязычном демографическом словаре «стержнем» теоретической демографии выступала система методов демографических исследований, поэтому последняя отождествлялась с математической демографией - формализованной, но все-таки единой наукой. Известный переведенный у нас двухтомник А. Сови «Общая теория населения» [1977], выступал неудавшейся попыткой содержательного оформления единой общей теории населения. Он включал в нее и некоторые факторы, влияющие на демографические процессы, а также отдельные направления обратного воздействия демографического фактора на экономику. О демографическом переходе как теоретической концепции в этой общей теории не упоминалось.

Соглашусь с мнением А.Г. Вишневского, что демографическая революция (переход) относится к теориям «может быть даже не только среднего уровня, как полагал в свое время Д. Коугил» [Cowgil 1970]. С моей точки зрения, теория демографического перехода (революции) может разрабатываться как общая теория воспроизводства населения - только как органическая часть общей теории населения, т.е. теории, объясняющей социальноэкономические (и экологические) причины и последствия этого воспроизводства (с достоинствами и недостатками, присущими абстрактным, т.е. содержательно «обедненным», общим теориям, понимаемым как теории, одинаковые для всех стран; но без таких теорий не обойтись, о чем мы, т.е. демографическая школа, зародившаяся и существующая на экономическом факультете МГУ, писали около 40 лет назад) [Система знаний... 1976].

Возможность использования характеристик «второго демографического перехода» (но меняющихся во времени), т.е. превращения теории демографического перехода (революции) в более содержательную с единым подходом и системой факторов (прежде всего в отношении семьи, ее социальной роли, развития человека, рождаемости) поддерживает Дж. Колдуэлл [Caldwell 2008: 421]. Таким образом, этапы первого демографического перехода он пытается частично (через изменения в семье и с семьей) объяснить, применяя методологию, используемую во втором, (но при отсутствии самой схемы второго демографического перехода), хотя некоторые специалисты в области демографической теории подчеркивают различия первого и второго демографических переходов [Lethaeghege 2010: 246]. Почти о том же справедливо (не могу сказать «обоснованно») пишет и А.Г. Вишневский, отмечающий, что в демографическом переходе существует несомненная корреляция между изменениями семейных нравов, статуса и форм брака и семьи, социальных ролей родителей, всего того, что можно назвать «демографическим поведением» людей (но первопричина - снижение смертности), меняется и тип демографического равновесия, хотя не совсем ясно, что это такое - «тип» равновесия (а не соотношение уровней, показателей смертности и рождаемости) [Вишневский 2014a: 21] .

\footnotetext{
${ }^{5}$ О различиях типа и режима воспроизводства населения и определяющем воздействии первого на второй
} школа МГУ также писала [Авдеев 2004]. В настоящее время речь, по моему мнению, в основном идет об 
В теорию эпидемиологического перехода социально-экономические факторы включаются (тоже в самом общем виде), хотя попытки ее интеграции в теорию демографического перехода и его этапы пока не увенчались успехом 6 .

Поддерживаю мнение, что и «второй демографический переход» - это вовсе не отдельный процесс со своими собственными независимыми детерминантами, а лишь закономерный этап первого (скорее, попытка содержательного объяснения демографического перехода). Дж. Колдуэлл старается [Caldwell 2008], как я поняла, хотя бы частично снять недостатки концепций первого и «второго» демографических переходов. В первом переходе внимание обращается на количественные изменения рождаемости и смертности (схема), во втором - на отношения (и их изменения), происходящие в семье, роли ребенка в ней, взаимоотношениях супругов и их жизненных целях, т.е. на перемены в самой семье и ее социальной роли (определяемые общественным развитием и развитием самого человека). При этом недостаточное внимание уделяется количественным индикаторам перехода (кроме утверждения о стабильно низкой рождаемости, не обеспечивающей хотя бы простое воспроизводство населения во втором переходе - "the lowest low fertility") [Caldwell 2008: 22]. Однако привлекает внимание попытка объяснить первый демографический переход этими изменениями, т.е. «вдохнуть» в него содержание, но не через эпидемиологический переход, а через изменения, происходящие с семьей; представить его как часть первого (т.е. единого) демографического перехода (может быть, помимо воли самого автора).

\section{КОЛИЧЕСТВЕННЫЕ (СХЕМА) И/ИЛИ КАЧЕСТВЕННЫЕ (СОДЕРЖАНИЕ) ИЗМЕНЕНИЯ В ТЕОРИИ ДЕМОГРАФИЧЕСКОГО ПЕРЕХОДА}

Выступая против формализации демографического перехода и сведения теории к количественным показателям, А.Г. Вишневский в то же время отмечает, что короткое определение демографического перехода - это переход от равновесия высокой смертности и рождаемости к новому равновесию низкой смертности и рождаемости, сохранению «демографической энергии». Это «сохранение демографической энергии» привело к изменению социальных механизмов (общественных норм?), управляющих воспроизводством населения (а не наоборот?), «пусковым механизмом» перехода явилось снижение смертности. Но автор как-то забывает о том, что «пусковым механизмом» снижения смертности явилось не изменение отношения людей к смерти, а социальноэкономические преобразования, рост уровня жизни, образования, развитие медицины и здравоохранения, изменения санитарии и гигиены (и соответствующих норм), что в свою очередь повлияло как на социально-экономическое развитие, так и на самого человека. Не просматривается пока анализ проблем этого «спускового механизма» снижения смертности, который остается «сжатым» и до сих пор, поскольку смертность снижается не

этапах режимов воспроизводства населения. Выход на содержательную общую теорию воспроизводства (как единство его режимов и типов) - задача на десятилетия. Она, конечно, не под силу одному ученому. Но термин «теория» означает «объясняющий» явление, процесс.

${ }^{6}$ Кроме того, в этой теории существует проблема факторов и соотношения заболеваемости и смертности на разных этапах перехода 
сама по себе, а только под влиянием системы социально-экономических факторов, определяющих и изменение самого человека ${ }^{7}$.

Иначе говоря, автор акцентирует внимание читателя на количественных индикаторах, которые по его же мнению отражать суть демографического перехода не могут. Остается не совсем понятно, почему же снизилась смертность и почему именно «демографическая система», необходимость ее самовоспроизведения (видимо, божественно заданная), но не социально-экономические условия влияют на человеческое поведение. По моему мнению, в такой общей теории не может быть человека, социальных групп, состоящего из них населения, имеющего определенный уровень образования, доходов, национальность, семейные традиции, ценностные ориентации, живущего в определенных социально-экономических, исторических и политических, страновых условиях. Отмечается, что внутренняя логика теории демографического перехода заключается в том и только в том, что снижение рождаемости выступает неотвратимым этапом цепной реакции, запущенной небывалым и необратимым снижением смертности [Вишневский 2014a: 8]. Это необходимый ответ на вызванное указанным снижением нарушение демографического равновесия (но все-таки «в пределах некоторой территории», что ведет к отрицанию общности теории, если только «общность» и «одинаковость» не одно и то же, да и для демографа «некоторая территория» звучит довольно неопределенно).

«Некоторая территория» - видимо, это страна или группа стран. Тогда демографический переход -теория не общая, а относящаяся к определенной территории, в которой территориальную (социальную, экономическую, политическую, историческую, национальную, религиозную и т.д.) специфику необходимо учитывать, на что постоянно указывает М.А. Клупт. Если демографическая система, как заявлено в работах А.Г. Вишневского, - это общее, тогда некорректно говорить о локальном, если не обратить внимание на один важный с моей точки зрения методологический вопрос, который прозвучал в работах научной школы МГУ в середине $70-$ х годов ${ }^{8}$. Странно выглядят и утверждения о возможности использовании этой общей теоретической конструкции в прогнозах населения отдельных стран, которые все, согласно той же точке зрения, не обязательно пойдут по одному пути [Вишневский 2014a].

\footnotetext{
7 Эта точка зрения понятна, поскольку в этом случае «провисает» понятие «самовоспроизводящейся» демографической системы вне системы социально-экономических факторов, объясняющих не ее воспроизведение, а изменения, в ней происходящие.

${ }^{8}$ Выдвигая гипотезу «всеобщего закона развития» населения, соотнося всеобщее и отдельное, мы приводили подход К. Маркса и Ф. Энгельса к анализу законов развития капитализма, отмечая, что всеобщее не означает «одинаковое» для каждой страны [Система знаний... 1976:79-82]. Всеобщие законы развития капиталистической формации строились ими на основе выведения экономических законов Англии, т.е. одной страны. Всеобщую теорию воспроизводства населения можно сформировать на основе анализа этого воспроизводства и одной страны с классическими этапами перехода (классической схемой перехода), включая в объяснение и социально-экономическое окружение «демографической системы».
} 


\section{УСЛОВИЯ ЖИЗНИ И ДЕМОГРАФИЧЕСКОЕ ПОВЕДЕНИЕ В ТЕОРИИ ДЕМОГРАФИЧЕСКОГО ПЕРЕХОДА}

Ученые, занимающиеся теорией демографического перехода, исследуют изменение социально-экономических условий (факторов) перехода, общественных норм (не обязательно обусловленных демографическими изменениями), системы ценностных ориентаций, мотивов, опираясь на отдельные исторические примеры (что часто делает и А.Г. Вишневский). Ученый одновременно отмечает и изменение человеческой демографической мотивации, но речь (поскольку это общая теория) ведется не о мотивах (или системе ценностей), а об абстрактом ценностно-рациональном и переходе от него к целерациональному (по М. Веберу) демографическому поведению. При первом виде поведения человек действует в соответствии с общественными нормами, полностью подчиняясь им, иногда даже в ущерб своим собственным интересам. С возрастанием степени человеческой свободы (которая произрастает, видимо, вне зависимости от социально-экономических условий, определяющих изменение и самих людей, свободу личности) человек действует согласно своим личным интересам. Такое противопоставление представляется несколько искусственным, поскольку общественный человек всегда интериоризирует нормы общества, в котором живет, воспринимая их как свои. Уже хорошо, что демографическое поведение человека на любой стадии демографического перехода теперь трактуется как рациональное. Этот подход (в основе своей философский), в принципе не отличается от нашего абстрактного подхода к общему закону народонаселения и его составной части - закону воспроизводства населения (хотя тогда, 40 лет назад, его именно за это и критиковали).

На мой взгляд, важно следующее утверждение: «Разумеется, все эти перемены произошли не сами по себе, они стали итогом тысячелетий экономического и социального развития человечества» [Вишневский 2014a: 11]. Видимо, как только демографические перемены начались, они перестали зависеть от социально-экономического и политического развития стран, изменений социальной структуры, семей, развития самого человека. Напрашивается вполне логичный вывод, что демографическая система как относительно независимая подсистема общества, оказывающая на него влияние, возникла с началом демографического перехода, а до него ее как системы не было. Об этой важной, как полагаю, проблеме историчности самой демографической системы я нигде не читала.

Более последователен, на мой взгляд, подход М.А. Клупта, утверждающего необходимость комплексного анализа социально-экономических отношений, институтов, политики в стране или группе стран, т.е. полагающего, что содержательная теория демографического перехода - это теория среднего уровня9 ${ }^{9}$ М.А. Клупт считает, что игнорирование цивилизационных различий и региональных особенностей препятствует формированию реалистической картины демографического прошлого, настоящего и будущего. Видение мира как совокупности изолированных и живущих исключительно по своим внутренним законам цивилизаций, равно как и жесткий детерминизм

\footnotetext{
${ }^{9}$ Сказала бы: «пока теория среднего уровня». Хотя, может быть, действительно наступил закат (временный или постоянный) так и не появившихся содержательных демографических гранд-теорий.
} 
«однолинейных» (т.е. прозападных) изменений во всех странах мира уходят в прошлое вместе с «гранд-теориями» XIX и первой половины XX века. Цивилизационные и региональные особенности объявляются недостойными внимания теоретиков «мелочами», «страновые нарративы (кейс-истории)» - предметом беллетристики, а не науки [Клупт 2014: 51].

В настоящее время, с моей точки зрения, спор между указанными авторами ведется некорректно в том смысле, что исследуются теории разного уровня: общая теория демографического перехода и теории воспроизводства населения отдельных стран или их групп, по определению более содержательные, с учетом которых общая теория и может быть (если может быть) создана. Общая теория демографического перехода более абстрактна и бессодержательна, чем теория «множественности современностей» (и не только «современностей»), поэтому пока она представляется мне схемой, «внутри которой» могут находиться содержательные, объясняющие демографические процессы теории (или теория - в зависимости от понимания того, что такое «общее») «среднего уровня». Для экономиста эти споры и сейчас выглядят странно, поскольку никто не отрицает необходимость существования общей экономической теории наряду с международной, институциональной, региональной, национальной экономиками как отдельными экономическими науками, имеющими свои теории.

Для формального решения этого противоречия между всеобщим и страновым (отдельным, включающим специфические черты воспроизводства населения стран и регионов) мы можем увеличивать число типов стран по специфике количественных показателей, их соотношения в этапах перехода, в длительности демографического перехода, пока не дойдем до типологии, каждый тип которой представит одна страна. Мы можем также анализировать «демографический переход» в городском и сельском населении страны, в каждом ее отдельном городе и сельском поселении. Мы можем даже изучить «демографический переход» в «Доме на набережной», существующем уже более трех поколений (срок, вполне достаточный для демографического перехода в современных развивающихся странах), иначе говоря, таким образом дискредитировать саму общую теорию.

\section{ПРОБЛЕМЫ РАЗВИТИЯ ОБЩЕЙ ТЕОРИИ ДЕМОГРАФИЧЕСКОГО ПЕРЕХОДА НА ОСНОВЕ МЕЖДИСЦИПЛИНАРНОГО ПОДХОДА}

Постараюсь уточнить не решенные, но обозначенные (что чрезвычайно важно) проблемы теории демографического перехода, которые прослеживаются в работах А.Г. Вишневского как наиболее квалифицированного в нашей стране ее исследователя (с наличием противоречий, которые как мешают, так и помогают их решению, поскольку привлекают внимание немногочисленных ученых в нашей стране, занимающихся общей теорией воспроизводства населения как теорией демографического перехода):

1. Демографическая система, ее определение, причины изменений. В своих фундаментальных работах [Вишневский 1976; 1982] автор проводил идею, что демографическая система - это люди и объединяющие их демографические отношения 
(специфические, но не социально-экономические), априорно исключив социальноэкономические отношения из демографической системы. Ученый придерживался (и сейчас делает то же самое) дисциплинарного строя науки, между тем как мы (школа экономического факультета МГУ) много лет назад отмечали, что для объяснения динамики демографических процессов нужен проблемный подход (как сейчас говорят, решение «кейсов», и на их основе - выработка стратегии решения проблемы, т.е. теорий среднего уровня одновременно с формированием определенных методологических «рамок» для последующей разработки общей теории населения (его воспроизводства). В МГУ изначально «разводились» понятия «тип воспроизводства населения» (система: люди и объединяющие их общественные отношения, включающая и управление) и «режим воспроизводства населения» (система количественных характеристик типа воспроизводства населения) [Авдеев 2004]. Изменившемуся типу воспроизводства населения не всегда соответствует изменение показателей его режима, которые еще предстоит «интегрировать» в концепцию демографического перехода, претендующую на роль общей теории (каковой, на мой взгляд, она и должна являться). Ясно, что одной науке это не под силу. Разработка содержательной общей теории демографического перехода (объясняющей ее этапы), полагаю, невозможна вне междисциплинарного подхода.

2. Проблемы междисциплинарности в демографии. Демография как система демографических наук изначально (в МГУ 40 лет) назад формировалась как междисциплинарная наука (по крайней мере, были попытки, в то время не увенчавшиеся успехом). Для ее развития необходимы были другие (более современные) статистические и математические методы, опора на изучение истории воспроизводства населения стран и регионов, экономических и социальных отношений, социологические исследования, хотя бы в начале системно - на примере страны «классического перехода» (как у К. Маркса и Ф. Энгельса - Англии). Работы школы МГУ в области демографической теории были в то время абстрактными, схоластическими, но они, как ни странно, предвидели или ставили проблемы современности. Переход от дисциплинарного строя науки к междисциплинарному уже полвека назад был вызван попытками перехода от предметного к проблемному исследованию воспроизводства населения - этапов и факторов перехода (междисциплинарность начинает снова развиваться, по крайней мере в экономике, недавно, в социологии в течение более длительного времени).

Не понимаю, почему включенные в демографическую систему отношения между людьми, объясняющие их воспроизводство, не могут быть экономическими, социальными, политическими, национальными, религиозными (но «интегрированными» на основе комплексного, точнее междисциплинарного, подхода для решения определенной демографической проблемы, в данном случае - объяснения исторических изменений (или этапа) воспроизводства населения). Население, его воспроизводство в свою очередь предстает как комплекс проблем, требующих решения. Общественную проблему можно решить, используя междисциплинарный подход (со всеми его сложностями - к примеру, формирования нового языка науки, единых исходных принципов, разработки стратегии и тактики решения проблемы учеными - представителями разных наук, их координации на каждом этапе исследования, обобщения полученных результатов и т.д.). Об этом мы снова начинаем говорить, в том числе на платформе экономического факультета МГУ, забыв о 
том, что впервые эти вопросы у нас же и были поставлены. Нынешние попытки интеграции уже существующих теорий эпидемиологического перехода, переходов в семье, миграционного перехода, пока что не менее абстрактных, чем концепция демографического перехода, создают лишь видимость междисциплинарности.

3. Начало формирования относительно самостоятельной демографической системы (об этом у нас не говорится, видимо, предполагается, что она как система существовала, пока воспроизводились люди), обусловленного снижением смертности. Тем более нигде не читала о ее конце (что, разумеется, не означает прекращение воспроизводства населения). Что явилось «спусковым крючком» снижения самой смертности, когда демографическая система, видимо, и стала независимой, начала изменяться по своим собственным законам, воздействуя на общественные отношения? Весьма возможно, она сформировалась как система в XVIII веке вместе со стабильной тенденцией снижения смертности. В связи с этим неисторичной представляется трактовка А.Г. Вишневским точки зрения Дж. Колдуэлла, что «демографическое у последнего попадает не в «базис», а в «надстройку» [Вишневский 2014a: 12]. Еще в 1976 г Дж. Колдуэлл [Caldwel 1976: 352] писал о едином экономико-демографическом способе производства, обусловливающем воспроизводство и устойчивость многопоколенной допереходной семьи и заинтересованность (прежде всего не родителей, а старшего поколения) в рождении детей, о рациональности демографического поведения на любом этапе исторического (и демографического) развития человечества («ценностно-рациональной» высокой рождаемости). Для меня это утверждение означает отсутствие до демографического перехода демографической системы как относительно самостоятельного образования и непосредственную включенность демографических процессов в процессы социально-экономические. О «надстройке» или «базисе» на общественном или индивидуальном уровне можно рассуждать в конце демографического перехода вместе с изменением значимости демографического фактора в общественном развитии, системы ценностей человека (определяемых не только демографической системой), мотивов его демографического поведения на каждом этапе его жизненного пути. Вот тогда и завершится формирование относительно независимой демографической системы. В отношении утверждения о влиянии сокращения смертности, в том числе детской и младенческой, на снижение рождаемости можно повторить слова самого А.Г. Вишевского, что здесь «не нужна никакая теория, их может перечислить, пусть и не с такой полнотой, любой «человек с улицы» [Вишневский 2014a: 16-17] ${ }^{10}$.

${ }^{10}$ Хотя Galor [2011] отрицает указанную зависимость. Эта научная «проверка», как и другие (к примеру, Принстонское исследование рождаемости или исследование Value of Children), на мой взгляд, некорректны в том смысле, что не учитывается единица времени: для демографического перехода - длина поколения. 


\section{«САМОРАЗВИТИЕ ДЕМОГРАФИЧЕСКОЙ СИСТЕМЫ» В ТЕОРИИ ДЕМОГРАФИЧЕСКОГО ПЕРЕХОДА}

Концепцию гомеостатического регулирования демографической системы (непосредственной зависимости рождаемости главным образом от уровня смертности, а не от социально-экономических факторов-условий) я называю демографическим рационализмом в противовес социально-экономическому рационализму - тоже достаточно ограниченному подходу. В концепции демографического рационализма (гомеостатического регулирования) человек как бы «разрывается» пополам: он всегда действует демографически рационально, но на определенных этапах демографического перехода - социально-экономически иррационально, противореча своим личным и семейным экономическим интересам (по крайней мере, на это противоречие пока не обращается внимание). Может быть, демографическая рациональность тоже исторически возникла в тесной связи с социально-экономической в едином, а не теоретически «разорванном», «носителе определенных отношений» (социально-экономических, демографических, культурно-исторических), т.е. в человеке (обществе)?

Единица измерения времени, необходимого для проверки гипотез относительно факторов изменения демографической системы, тоже не формальный (как кажется на первый взгляд) вопрос. Если речь идет о демографической системе (понятии высокой степени абстракции), то единица времени, видимо, не может быть меньше длины поколения. Все, что происходит внутри этого промежутка времени, ни доказать, ни опровергнуть общую теорию, скорее всего, не может - это совершенно справедливо отмечает А.Г. Вишневский. Современная наука требует доказательств (проверок) теории, а для таких проверок нужны поколения демографов (в «связке учитель - ученик»). М.А. Клупт отмечает (ссылаясь на работу ван Далена и А. Хенкенса [Van Dalen, Henkens 2012]), что недавний всемирный опрос демографов отражает мнение большинства: статус ученого в демографии определяется, прежде всего, его достижениями в проведении эмпирических исследований. Феномен «зависимости от колеи» силен во всех человеческих сообществах, и демография, вероятно, останется (я бы все-таки сказала «пока остается») в высокой степени эмпирической дисциплиной [Клупт 2014: 51]. Эмпирические исследования, могут быть путем к прокладыванию этой «общей колеи», в пределах которой существуют частные и отдельные теории (демографического перехода страны, перехода в семье, рождаемости, эпидемиологического перехода, миграционного перехода) ${ }^{11}$. Кто будет прокладывать «общетеоретическую дорогу», неясно, если молодежь сейчас увлечена относительно примитивными (но эмпирически проверяемыми) схемами демографического поведения (естественно, западными), используя наиболее «модные» из них, переходя от одной к другой, а при таком подходе трудно разработать общую теорию.

Общность теории предполагает органическое единство частных теорий отдельных демографических процессов, прежде всего рождаемости, степени ее зависимости от социально-экономических, культурных, и других факторов. Сейчас мы наблюдаем попытки

11 Терминологию, может быть стоит изменить: демографическая революция как общая теория воспроизводства населения и частные переходы. 
связать ее динамику с развитием [Bryant 2010]. Совершенно справедливо, с моей точки зрения, утверждение А.Г. Вишневского ${ }^{12}$, что развитие теории демографического перехода не было органичным. Оно напоминало расширение дома путём постоянного добавления к нему различных пристроек, каждая из которых хотя и сохраняла некоторую связь с основным домом, но не выступала частью единого целого. Среди этих пристроек есть «эпидемиологический переход», «второй демографический переход», «третий демографический переход» и т.д. Теория распадается на отдельные части. «Дробление» единого демографического перехода на множество отдельных переходов ведет к тому, что при анализе каждого из них развивается самостоятельная аргументация, оторванная от корней «материнской» теории [Вишневский 2014a: 13]. Но в этих «пристройках» в большей степени, чем в общей теории, присутствуют социально-экономические условия-факторы, что признает А.Г. Вишневский [Вишневский 2014b].

В фундаментальной работе «Демографическая модернизация России» [2006] описание перехода начинается не со смертности, как следовало бы ожидать, а с изменений брачно-семейных отношений (о необходимости включения в теорию изменений брачности и семьи писал Д. Колдуэлл). На этом основана концепция «второго демографического перехода», об этом говорят и сторонники концепции «институционального кризиса семьи» как глубинной основы снижения рождаемости. В то же время вполне возможно, что каждой (уже частной) теории и не хватает «общих рамок», предлагаемых концепцией демографического перехода.

Соглашусь и с точкой зрения, что «в глобализации демографического перехода заключается его новая фаза, которую можно было бы назвать «третьим демографическим переходом», но ее никак нельзя свести просто к изменению состава населения принимающих стран, хотя это изменение и в самом деле имеет место. Суть ее заключается в превращении всего мирового населения в систему сообщающихся сосудов, в которой все демографические процессы взаимосвязаны между собой и не могут быть поняты с позиций какой-либо одной из частей этой системы» [Вишневский 2014a: 23].

\section{ФОРМИРОВАНИЕ ОБЩЕЙ ТЕОРИИ}

Я вижу два пути формирования общей теории населения как теории демографического перехода. Первый путь: анализ взаимодействия социально-экономических и демографических исторических изменений рядом наук, изучающих конкретное общество (страну, страны) на основе решения комплекса проблем, не решенных до сих пор ни обществоведами, ни демографами, заявившими о необходимости междисциплинарного подхода к изучению народонаселения десятилетия назад. И к настоящему времени такой подход не реализован из-за недостаточной для формирования теории развитости комплексных историко-социолого-экономико-демографических исследований типичной страны или их групп (и национальных, религиозных, географических и других кейс-

12 В основном цитирую этого ученого, потому что именно он последовательно разрабатывает в нашей стране теорию демографического перехода как общую теорию воспроизводства населения, о которой мы (МГУ) както уже и забыли. 
историй, по выражению М.А. Клупта [Клупт 2014: 51]). Тем более он не был реализован и 40 лет назад (мы больше стали говорить о комплексном, чем о междисциплинарном подходе, понимая его сложности и невозможность для нас его реализации в то время).

При обобщении результатов исследований демографической проблемы (например, объяснения этапов снижения рождаемости) в группе стран отдельными науками неизбежно исключаются содержательные, важные для воспроизводства населения (в данном случае рождаемости) региона социально-экономические, политические, национальные, религиозные и другие условия-факторы. Для решения этой методологической проблемы в качестве «эталона» можно использовать содержательную теорию классического демографического перехода (включающую как схему этапов, так и их социальноэкономические факторы) в стране, понимаемой как «типичная страна перехода». При таком подходе «общность» не означает «одинаковость» этапов перехода и их факторов во всех странах. В эпоху глобализации общность переходит в «одинаковость», поскольку границы между странами размываются и воспроизводство населения каждой страны постепенно приближается к «эталону».

Второй путь проще (по этому пути идет А.Г. Вишневский): «выбросить “мягкое социальное окружение" демографии [Cowgil 1970: 6], оставив только демографические процессы - “жесткое демографическое ядро”». В результате общим в этой общей теории остается «взаимодействие рождаемости и смертности», поведение «целе-рационального» человека как их «содержательная» общественная основа. Выводимые таким образом общие законы, понимаемые как законы общего, абстрактного населения вообще, могут быть лишь статистическими или математическими законами, поскольку эти науки, как указывалось, обеспечивают формальную междисциплинарность. Отдельные примеры непрерывных рядов процессов рождаемости и смертности на коротком для демографического перехода промежутке времени или некоторые показатели, характеризующие рождаемость и смертность по отдельным странам (как это часто делает А.Г. Вишневский), с точки зрения его концепции методологически неверны и теорию не доказывают. В то же время такие примеры оправданы с позиции М.А. Клупта.

Соотношение частных теорий зависит от общей теории. С другой стороны, содержание общей теории обусловлено частными теориями. Об этом мы тоже говорили около 40 лет назад (в то время наши идеи о комплексном и междисциплинарном подходе к формированию теории населения (теории воспроизводства населения, включающей его факторы, социально-экономические условия и последствия), о соотношении общего и отдельного, специфического ученые считали схоластическими, что было совершенно справедливо). Но это знание помогает нам «узнать забытое», не «изобретать велосипед» сегодня (хотя сейчас в области теории этим мы вроде бы и занимаемся). Когда время таким исследованиям пришло, такое знание дает возможность лишь вспомнить о том, что было, и не терять время на повторение собственных ошибок, а идти дальше. Говоря о всеобщем законе развития народонаселения, включающем его воспроизводство, факторы и последствия, его качественные характеристики, мы отмечали, что ученые, изучавшие развитие специфических отношений, являвшихся предметами их наук, фактически изучали отдельные аспекты общей теории народонаселения, которая должна представлять эти изменения как моменты единого процесса, в центре которого - воспроизводство населения 
[Система знаний... 1976: 78]. Сейчас то же можно сказать о демографическом переходе (демографической революции). В нашей стране в настоящее время плодотворные, на мой взгляд, исследования А.Г. Вишневского вызывают небольшой интерес ученых, а тем более практиков, как и наши 40 лет назад.

Общая теория демографического перехода в настоящее время (глобализация), еще не став содержательной, уже становится эклектичной, в ней глобальные тенденции, отражающие взаимодействие стран с их экономико-демографической и социальной спецификой, будут обращать на себя все большее внимание как ученых, так и политиков. Как только ученый пытается объяснить демографический переход через изменения социально-экономических отношений, условий, общественных норм, потребностей, мотивов поведения, ему приходится переходить к другому уровню исследования: к конкретной стране, находящейся на определенной стадии своего социального и экономического развития (в настоящее время учитывать и глобализацию, взаимодействие стран).

\section{ВОЗМОЖНЫЕ СТРАТЕГИИ ФОРМИРОВАНИЯ ТЕОРИИ ДЕМОГРАФИЧЕСКОГО ПЕРЕХОДА}

Стратегия А.Г. Вишневского: влияние снижения смертности на сокращение рождаемости (через переход от «ценностно-рационального к целерациональному» поведению), фактически означающая переход от одного равновесия демографической системы к другому (с низкими уровнями смертности и рождаемости). Эта стратегия сыграла и еще играет важную роль в исследовании общих тенденций воспроизводства населения, поскольку ставит изучение воспроизводства населения в определенные научные рамки, прививая молодым исследователям определенную «научную культуру». Но не «поддержанная» движением «снизу» (от анализа демографических проблем, страновых социально-экономико-историко-демографических исследований), ее абсолютизация может привести в тупик даже через «включение» (не скажу интеграцию) в нее теорий эпидемиологического перехода, модернизации семьи, теорий рождаемости (тоже пока еще схоластических, односторонних). Как правильно указывает А.Г. Вишневский, и теория эпидемиологического перехода распадается на ряд подходов-теорий, ее содержательные этапы не всегда соответствуют этапам демографического перехода [Вишевский 2014b: 68].

Стратегия - расширение предметов исследования отдельных наук, прежде всего экономической и социологической, за счет включения ранее не свойственной им демографической проблематики. Начало такому «расширению» положили 60-70 годы прошлого века. Так, например, Г. Беккер утверждал, что «экономический подход имеет уникальную силу, т.к. он может представить человеческое поведение как единое целое» [Sociological Economics...1979: 20]. По его мнению, общая теория любой социальной науки - это экономическая теория, что напоминает «теоретико-экономический империализм», т.е. насильственный захват чужой территории, предметной области другой науки, объявление ее своей собственностью (а значит, и ее примитивизацию). 
И еще одна возможная, на мой взгляд, трудно реализуемая стратегия - это развитие демографо-экономико-историко-социологического подхода на основе современных математических и статистических методов анализа «классического перехода» ${ }^{13}$, в котором бы органично сочетались классические черты социально-экономического развития и формальные характеристики демографического перехода (схема этапов). Он позволяет интегрировать недемографическое и демографическое специфическое развитие населений отдельных стран. Но здесь и в настоящее время для формирования содержательной общей теории демографического перехода остается множество «подводных камней» (если это не формализованные математические модели) [Коротаев и др. 2010].

\section{ЗАКЛЮЧЕНИЕ}

Общей содержательной теории демографического перехода я пока не вижу. Есть только схема его этапов, по которой шли (или идут) страны мира (с некоторыми специфическими «отклонениями»). Общее для всех стран то, что в начале перехода смертность и рождаемость были высокими, а темпы роста населения - низкими, а в конце перехода смертность и рождаемость стали низкими, как и темпы роста населения. В процессе перехода происходит временное повышение темпов роста населения. Утверждение влияния снижения смертности, в том числе детской и младенческой, на сокращение рождаемости (с этим утверждением никто и не спорит) пока еще не отвечает на вопрос, почему семья хочет иметь определенное число детей, «подстраиваясь» под снижение смертности. Есть отдельные теории: эпидемиологического перехода, множество абстрактных теорий рождаемости, «исторические» теории переходов в брачности и семье, гендерного перехода.

Основной вопрос: как понимается общее (всеобщее). Первое направление его решения - междисциплинарный подход и формирование теории демографического перехода, его этапов, системы основных факторов перехода одной страны «классического» демографического перехода, например Англии. При таком подходе не обязательно каждая страна должна повторять путь других стран и его объяснение. Второе направление - анализ демографического перехода отдельных стран мира. Затем - обобщение полученных результатов. Скорее всего, при таком обобщении исследователи (а это несколько поколений) «потеряют» важнейшие для отдельной страны, но неважные для других стран факторы перехода, выйдут на схему, включающую влияние смертности на рождаемость, может быть, отдельные весьма абстрактные утверждения о специфике рационального поведения человека вообще. По этому направлению формирования общей теории демографического перехода идет А.Г. Вишневский. Можно ли сейчас создать содержательную общую теорию демографического перехода для стран, которые его не закончили, в условиях «многообразия современностей» в глобальном мире при наличии в

\footnotetext{
13 Критерий - классическая схема этапов демографического перехода (не забывая о том, что при этом необходимо абстрагироваться от некоторых особенных социально-экономических факторов страны «классического перехода», значимых для воспроизводства населения в ней, но не свойственных другим странам, а также и о том, что социальные группы страны имели свою репродуктивную, витальную, миграционную стратегию, из которых складывалась эта классическая схема).
} 
каждой стране различных условий-факторов воспроизводства населения, их глобальном взаимодействии, - сомнительно.

Объяснения демографических переходов ${ }^{14}$ в странах мира как отдельных теоретических конструкций, как теорий «среднего уровня» при отрицании возможности выхода на общую теорию существуют для разных стран (в нашей стране этой отдельной теорией занимается M.A. Клупт, интересны работы D. Caldwell, B. Mitchell, R. Lee). B заключение хочу выразить благодарность А.Г. Вишневскому за продолжение работы в области теории воспроизводства населения, за независимость «от колеи», за попытки «построить дорогу» (а не «колею») несмотря на то, что такие фундаментальные исследования, «гранд-теории», видимо, не приносят непосредственной пользы (не имеют «практического значения») ни практикам, ни политикам. Может быть, «гранд-теории» XIX - первой половины XX века, как утверждает М.А. Клупт, остались в прошлом (как и демографический переход в развитых странах), но без них закономерности воспроизводства населения (а значит, и их исследование) распадаются на пока слабо связанные между собой обрывки (если это не формализованные демографические модели).

\section{ЛИТЕРАТУРА}

Авдеев А.А. (2004). Исторические типы народонаселения докапиталистических формаций. М: Издательство МГУ.

Вишневский А.Г. (1976). Демографическая революция. М.: Финансы и статистика.

Вишневский А.Г. (1982). Воспроизводство населения и общество: история, современность, взгляд в будущее. М.: Статистика.

Вишневский А.Г. (2014а). Демографическая революция меняет репродуктивную стратегию вида homo sapiens // Демографическое обозрение. T.1. №1: 6-33. URL: http://demreview.hse.ru/2014--1/120991102.html (дата обращения: 23.02.2015).

Вишневский А.Г. (2014b). Смертность в России: несостоявшаяся вторая эпидемиологическая революция // Демографическое обозрение. T.1. №4: 5-40. URL: http://demreview.hse.ru/2014--4.html (дата обращения: 23.02.2015).

Демографическая модернизация России, 1900-2000 (2006) / Под ред. Анатолия Вишневского. М.: Новое Издательство.

Клупт М.А (2014). Парадигмы и оппозиции современной демографии // Демографическое обозрение. Т.1. №1: 34-56. URL: http://demreview.hse.ru/2014--1/120991102.html (дата обращения: 23.02.2015).

Коротаев А.В., Д.А. Халтурина, А.С. Малков, Ю.В. Божевольнов, С.В. Кобзева, Ю.В. Зинькина (2010). Законы истории: математическое моделирование и прогнозирование мирового и регионального развития. М.: 24-39.

Система знаний о народонаселении (1976) / Под ред. Д.И. Валентея. М.: Статистика.

14 Я бы использовала термин «закономерных демографических изменений», хотя для развитых стран мира, в которых демографический переход закончился, было бы и возможно создание общей теории демографического перехода. 
Сови А. (1977). Общая теория населения. Т.1 и Т.2. М.: Прогресс.

Bryant G. (2010). Theories of fertility decline and the evidence from development indicators // Population and Development Review. 33(1): 101-127.

Caldwell J.C. (1976). Theory of fertility, from high plateau to destabilization // Population and Development Review. 16 (2): 561-588.

Caldwell J. C. (2008). Three fertility compromises and two transitions // Population Research and Policy Review. 32(4): 427-446.

Cowgill D.O. (1970). Transition theory as a general population theory // Social Demography. 2 (12): 231-265.

Galor O. (2011). The demographic transition: causes and consequences // NBER Working Paper No. 17057: 124-157. URL: http://www.nber.org/papers/w17057/ (дата обращения: 24.12.2012).

Lesthaeghe R. (2010). The unfolding story of the second demographic transition // Population Research and Policy Review. 3 (44): 232-261.

Soociological Economics (1979). London: Sage Publish.

Szoltysek M. (2007). Science without laws? Model building, micro histories and the fate of the theory of fertility decline // Historical Social Research. 32(2): 10-41

Van Dalen H., Henkens K. (2012). What is on a demographer's mind? A worldwide survey. Demographic Research. 26: 363-408. URL:http://www.demographicresearch.org/Volumes/Vol26/16/. (дата обращения: 23.02.2015). 


\title{
THE DEMOGRAPHIC TRANSITION: DEBATE ABOUT THEORIES OF DIFFERENT LEVELS
}

\section{NATALIYA ZVEREVA}

\author{
NATAliya Zvereva. Lomonosov Moscow State University. Russia. \\ E-MAIL: zvereva52@yandex.ru. \\ DATE RECEIVED: November 2014.
}

\begin{abstract}
The subject of the article are the problems of developing the theory of demographic transition (demographic revolution) arising from the confusion in demographic theory of the general and the specific features of population reproduction of countries, of its quantitative and qualitative changes, from the need to develop a consistent overall demographic theory based on a multidisciplinary approach. The purpose of the work is, by analyzing the two main points of view in Russia on the theory of demographic transition, to show their internal contradictions. The use of general philosophical methodology (analysis, synthesis, an integrated and interdisciplinary approach, the ratio of general and specific, historical and demographic generalizations makes it possible to interrelate this theory with the still unsolved problems of the interdisciplinary approach of human reproduction studies. It is shown that scientists are arguing about theories of different levels, and that the development of a general theory of population reproduction directly depends on the choice of strategies of its formation, the most important of which is the demographic-economic-historical-sociological approach.
\end{abstract}

Key words: population reproduction, mortality, fertility, demographic transition theory, demographic revolution, demographic system, type of motivation of demographic behavior.

\section{REFERENCES}

Avdeev A. (2004). Istoricheskiye tipi narodonaseleniya dokapitalisticheskih formatsiy [Historical population types of pre-capitalist formations]. M.: MSU.

Bryant G. (2010). Theories of Fertility Decline and the evidence from Development Indicators / /Population and Development Review. 34(1): 101-127.

Caldwell J.C. (1976). Theory of Fertility, from High Plateu to Destabilization // Population and Development Review. 16 (2): 561-588.

Caldwell J. C. (2008). Three Fertility Compromises and Two Transitions // Population Research and Policy Review. 32(4):427-446.

Cowgill D.O. (1970). Transition theory as a general population theory // Social Demography. 2 (12): 231-265.

Demographicheskaiya modernizatcia Rossii, 1900-2000 (2006) [Demographic modernization in Russia, 1900-2000]/ A. Vishnevsky, ed. M.: Novoye Izdatelstvo.

Galor O. (2011). The demographic transition: causes and consequences // NBER Working Paper No. 17057: 124-157. URL: http://www.nber.org/papers/w17057/ (accessed: 24.12.2012).

Klupt M.A. (2014). Paradigmi i oppozitsii sovremennoy demographii [Paradigms and oppositions of modern demography] // Demographic Review. Vol.1. №1: 34-56. URL: http://demreview.hse.ru/2014--1/120991102.html (accessed: 23.02.2015).

Korotayev A., D. Khalturina, A. Malkov, Yu. Bozevolnov, S. Kobzeva, Yu. Zinkina (2010). Zakoni istorii: matematicheskoye modelirovaniye i prognozirovaniye mirovogo i 
regionalnogo rasvitiya [The laws of history: mathematical modeling and forecasting of the global and regional development]. M.: 24-39.

Lesthaeghe R. (2010). The unfolding story of the second demographic transition // Population Research and Policy Review. 3(44): 232-261.

Sistema znaniy o narodonaselenii (1976) [The system of knowledge about population] / D.I. Valenteiya, ed. M.: Statistica.

Sociological Economics (1979). London: Sage Publish.

Sauvy A. (1977). Obshchaiya teoriya naseleniya [General population theory]. T.1, 2. M.: Progress.

Szoltysek M. (2007). Science without laws? Model building, micro histories and the fate of the theory of fertility decline // Historical Social Research. 32(2): 10-41.

Van Dalen H., Henkens K. (2012). What is on a demographer's mind? A worldwide survey. Demographic Research. 26: 363-408. URL:http://www.demographicresearch.org/Volumes/Vol26/16/. (accessed: 23.02.2015).

Vishnevsky A. (1976). Demograficheskaya revolutsia [Demographic revolution]. M.: Statistica.

Vishnevsky A. (1982). Vosproizvodstvo naseleniya i obschestvo: istoriya, sovremennost, vzgliad $\mathrm{v}$ byduschee. [Human reproduction and society: past, present, looking to the future]. M.: Statistica.

Vishnevsky A. (2014a). Demograficheskaya revolyutsiya menyayet reproduktivnuyu strategiyu vida Homo sapiens [The demographic revolution is changing the reproductive strategy of Homo sapiens] // Demograficheskoye obozreniye [Demographic Review] Vol.1. № 1: 6-33. URL: http://demreview.hse.ru/2014--1/120991102.html (accessed: 23.02.2015)

Vishnevsky A. (2014b). Smertnost v Rossiyi: nesostoyavschayasya vtoraya epidemiologicheskaya revolutsia [Mortality in Russia: the second epidemiologic revolution that never was] // Demograficheskoye obozreniye [Demographic Review]. Vol.1. №4: 5-40. URL: http://demreview.hse.ru/2014--4.html (accessed: 23.02.2015). 